ISSN 2466-2232

Online ISSN 2466-2100

\title{
Effect of Aluminum on Thermally Induced $\varepsilon$-Martensite for Fe-Mn-C TWIP Steels
}

\author{
Myungjin Lee*, Chulho Park*, Eunjoon Chun**, Juseung Lee***, and Namhyun Kang*,† \\ *Department of Materials Science and Engineering, Pusan National University, Busan, 46241, Korea \\ **Busan Laser Application Support Center, Korea Institute of Machinery \& Materials, Busan, 46744, Korea \\ ***Land Systems Center, Defense Agency for Technology and Quality, Changwon, 51474, Korea
}

†Corresponding author : nhkang@pusan.ac.kr

(Received January 6, 2019 ; Revised January 31, 2019 ; Accepted February 1, 2019)

\begin{abstract}
Cold-rolling of hot-rolled plate of Fe-18.7Mn-0.61C-1.4Al (Al-TWIP) steel was identified with an austenite single phase through the entire thickness, and that of Fe-17.8Mn-0.57C (TWIP) steel was composed of $\varepsilon$-martensite and austenite phases from the surface to a thickness of $\sim 45 \mu \mathrm{m}$. Electron back-scattered diffraction (EBSD), glow discharge spectrometry (GDS), and transmission electron microscopy (TEM) were conducted to investigate the $\varepsilon$-martensite transformation of TWIP steel. In TWIP steel, thermally induced $\varepsilon$-martensite transformation was produced since the surface austenite stability decreased due to surface decarburization. The thickness of $\varepsilon$-martensite $(\sim 45 \mu \mathrm{m})$ was coincident with the depth at which $0.45 \mathrm{wt} \% \mathrm{C}$ of TWIP steel was achieved. However, the TWIP steel with added Al increased the austenite stability of the surface layer and suppressed $\varepsilon$-martensite transformation.
\end{abstract}

Key Words : TWIP steel, Aluminum, Thermally induced $\varepsilon$-Martensite, Decarburization, Glow discharge spectrometry

\section{Introduction}

TWIP steel having high strength and formability is under active research following environmental and safety regulations in the automobile industry ${ }^{1-5}$. TWIP steel is high-manganese steel containing more than $15 \%$ manganese and mechanical twins that are generated during plastic deformation are responsible for its improved elongation, high strain-hardening rate, and excellent strength. Therefore, it has reasonable processability including weldability and can meet the requirements of the automobile industry ${ }^{6-11)}$.

The major deformation mode of TWIP steel is determined by the stacking fault energy (SFE). SFE determines the plastic-deformation mode such as martensite transformation, deformation twinning, and slip modes in TWIP steel ${ }^{12,13)}$. Sato et al. reported that the mechanical transformation from austenite to $\varepsilon$-martensite was favored for SFE lower than $20 \mathrm{~mJ} \mathrm{~m}^{-2}$, whereas the formation of mechanical $\varepsilon$-martensite was suppressed and deformation twinning occurred when SFE was higher than $20 \mathrm{~mJ} \mathrm{~m}^{-2}$ in Fe-Mn-Al TWIP steels ${ }^{14)}$. Alline et al. calculated that mechanical twinning occurred at SFE between 12 and $35 \mathrm{~mJ} \mathrm{~m}^{-2}$ in Fe-22Mn0.6C TWIP stee ${ }^{15) .}$ Frommeyer et al. reported that mechanical $\varepsilon$-martensite transformation occurred at low SFE $\left(<16 \mathrm{~mJ} \mathrm{~m}^{-2}\right)$ and the formation of twin deformation was favored for SFE between 16 and $25 \mathrm{~mJ} \mathrm{~m}^{-2}$ in stable austenitic phases ${ }^{16}$. $\varepsilon$-martensite can be produced by strain-induced transformation and thermally induced transformation (by heat treatment) ${ }^{17,18)}$. Thermally induced $\varepsilon$-martensite is produced with lower SFE than strain-induced $\varepsilon$-martensite ${ }^{19)}$.

The primary factors that determine SFE are chemical composition and deformation temperature ${ }^{12,13)}$. Aluminum (Al) is a very effective element for increasing SFE and suppresses $\varepsilon$-martensite transformation in TWIP steel ${ }^{14,20)}$. Kim et al. reported that SFE increased by $17 \mathrm{~mJ} \mathrm{~m}^{-2}$ when $1.5 \mathrm{wt} \% \mathrm{Al}$ was added to $\mathrm{Fe}-18 \mathrm{Mn}-0.6 \mathrm{C}$ TWIP steel ${ }^{13)}$. The addition of $\mathrm{Al}$ was shown to inhibit $\varepsilon$ -martensite transformation and delayed fracture when 
the cup deformation of Fe-18Mn-0.6C TWIP steel was conducted $^{21)}$. However, the reason was not studied for the $\varepsilon$-martensite transformation for Fe-18Mn-0.6C steels due to the addition of Al. The objective of this study is to identify the mechanism by which $\mathrm{Al}$ content affects $\varepsilon$ martensitic transformation in Fe-17.8Mn-0.57C TWIP and $\mathrm{Fe}-18.7 \mathrm{Mn}-0.61 \mathrm{C}-1.4 \mathrm{Al}$ TWIP steels.

\section{Materials and methods}

The chemical compositions of specimens used in this experiment were $\mathrm{Fe}-17.8 \mathrm{Mn}-0.57 \mathrm{C}$ and $\mathrm{Fe}-18.7 \mathrm{Mn}-0.61 \mathrm{C}$ 1.4Al, which are referred to as 'TWIP' and 'Al-TWIP', respectively. Fig. 1 shows the detailed conditions for manufacturing the TWIP and Al-TWIP steels. Sample ingots of thickness $25 \mathrm{~mm}$ were fabricated using a high-frequency vacuum melting furnace. Slab reheating in air was conducted at $1200{ }^{\circ} \mathrm{C}$ for $1 \mathrm{~h}$. After slab reheating, ingots were air-cooled to room temperature after hot rolling to $2.5 \mathrm{~mm}$ thickness and the sheets were cold-rolled to the final thickness of $1.25 \mathrm{~mm}$ at room temperature. Finally, the sheets were water-cooled after recrystallization heat treatment at $900{ }^{\circ} \mathrm{C}$ for $1 \mathrm{~min}$ to prevent carbide precipitation ${ }^{21)}$.

The specimens were mechanically polished and etched with $3 \%$ Nital solution, $10 \%$ sulfuric acid $\left(\mathrm{H}_{2} \mathrm{SO}_{4}\right)$, and $10 \%$ aqueous sodium metabisulfite $\left(\mathrm{Na}_{2} \mathrm{~S}_{2} \mathrm{O}_{5}\right)$ solution. The microstructures of TWIP and Al-TWP steels were examined using light optical microscopy (LOM). Electron back-scattered diffraction (EBSD), transmission electron microscopy (TEM), and X-ray diffraction (XRD) were conducted to identify the phases. XRD using a $\mathrm{Cu}-\mathrm{K} \alpha$ target was scanned from 30 to $100^{\circ}$, with step size of $0.02^{\circ}$ and scan speed of $1.0^{\circ} \mathrm{min}^{-1}$. Using a focused ion beam system, phase identification under the surfaces of specific microstructures was conducted with TEM. Glow discharge spectrometry (GDS) measured carbon, manganese, and aluminum contents from the surface in the thickness direction.

\section{Results and discussion}

Fig. 2 shows the X-ray diffraction patterns of TWIP

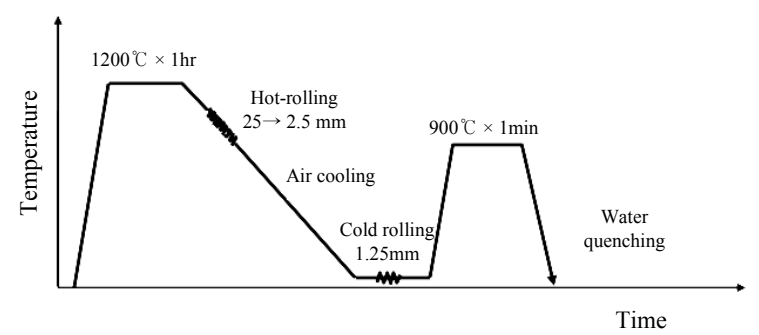

Fig. 1 Schematic illustration of the manufacturing conditions of TWIP and Al-TWIP steels

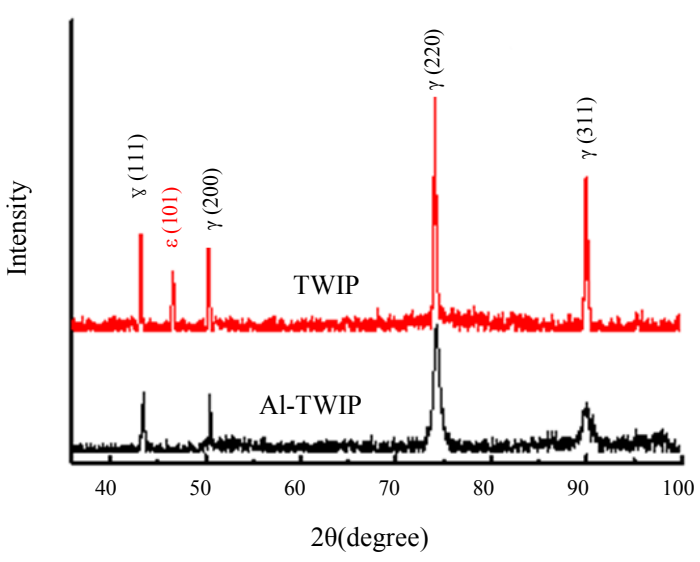

(a)

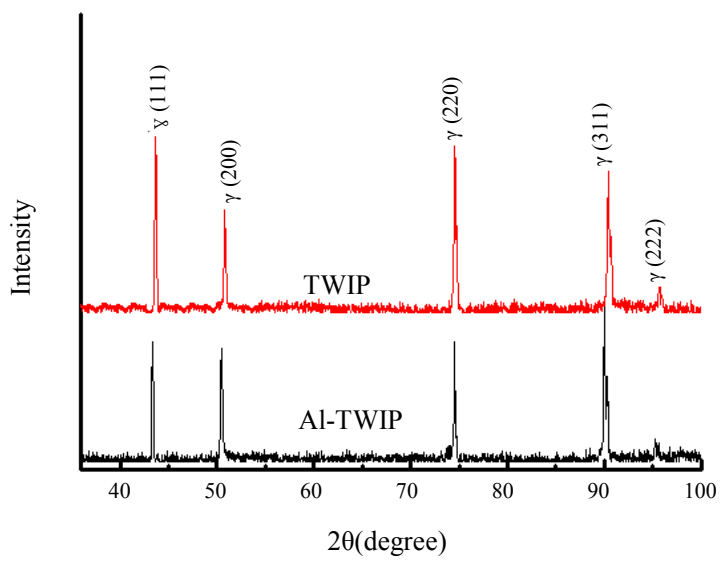

(b)

Fig. 2 X-ray diffraction patterns of TWIP and Al-TWIP steels: (a) $10 \mu \mathrm{m}$ from the surface and (b) $50 \mu \mathrm{m}$ from the surface

and Al-TWIP steels after cold rolling followed by recrystallization heat treatment. The XRD pattern was measured $10 \mu \mathrm{m}$ from the surface. The Al-TWIP steel indicated full austenite phase and the TWIP steel showed $\varepsilon$-martensite in addition to austenite. Fig. $2 \mathrm{~b}$ is the diffraction pattern measured approximately $50 \mu \mathrm{m}$ from the surface. Austenite single phases appeared in the XRD patterns of both TWIP steels. The formation of $\varepsilon$-martensite varied in TWIP steel with respect to the thickness. However, the Al-TWIP steel showed the austenite phase regardless of thickness.

Phase analysis using EBSD was conducted to confirm martensite transformation of the surface regions in TWIP and Al-TWIP steels after polishing the surfaces approximately $10 \mu \mathrm{m}$ to remove the scale layers. Fig. 3 shows the EBSD phase maps of the cross-sections of TWIP and Al-TWIP steels. The red-colored area of the phase map is austenite (fcc) and the green-colored area is $\varepsilon$-martensite (hcp). Fig. 3a shows that TWIP steel had $\varepsilon$-martensite from the surface to a depth of $\sim 30 \mu \mathrm{m}$ and the volume fraction of $\varepsilon$-martensite decreased while ap- 


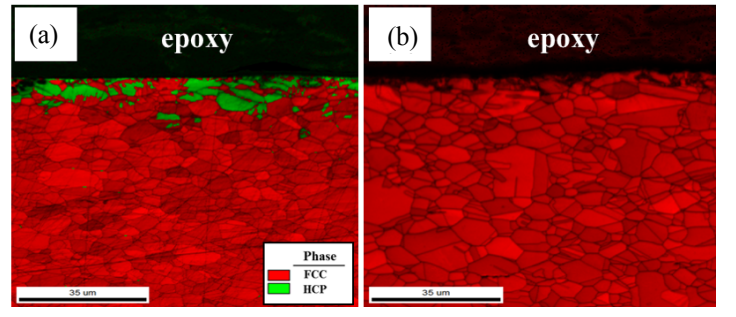

Fig. 3 EBSD phase maps of the cross-sections of (a) TWIP steel and (b) Al-TWIP steel
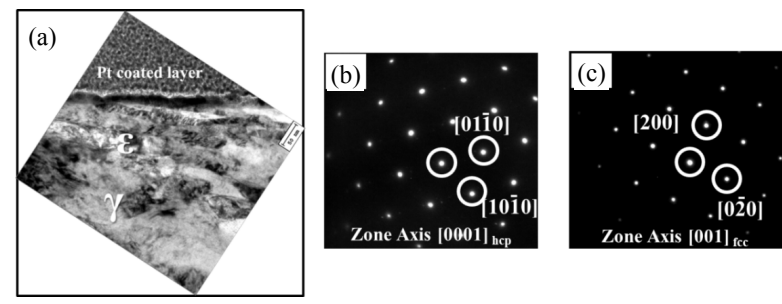

Fig. 4 TEM micrographs of TWIP steel: (a) cross-section below surface, (b) diffraction pattern of $\varepsilon$-martensite, and (c) diffraction pattern of austenite

proaching the center of the specimen. Considering the removal of the outermost-surface layer $(\sim 10 \mu \mathrm{m})$ in TWIP steel, the thickness of $\varepsilon$-martensite measured using $\operatorname{EBSD}(\sim 40 \mu \mathrm{m})$ was nearly coincident with that $(\sim 50 \mu \mathrm{m})$ measured using XRD (Fig. 2b). Al-TWIP steel indicated a single austenite phase at all thicknesses, as shown in Fig. $3 b$.

Fig. 4 presents a TEM micrograph showing the crosssectional microstructure of TWIP steel. The lath shape of $\varepsilon$-martensite was observed near the surface of TWIP steel (Fig. 4a). Figs. 4b and 4c show the diffraction patterns of $\varepsilon$-martensite (hcp) and austenite (fcc), respectively. TEM analysis confirmed the existence of $\varepsilon$-martensite in TWIP steel.

Fig. 5 shows the optical microstructures of TWIP and Al-TWIP steels measured at the position of quarter thickness. Both specimens indicated polygonal grains of recrystallized austenite and there were no indications of $\varepsilon$-martensite and elongated grains due to rolling. The

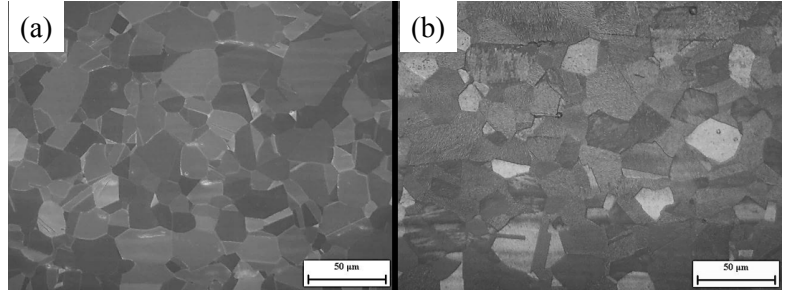

Fig. 5 Optical micrographs after recrystallization heat treatment for (a) TWIP steel and (b) Al-TWIP steel

specimens were water-cooled after recrystallization heat treatment at $900{ }^{\circ} \mathrm{C}$ for $1 \mathrm{~min}$. Therefore, the $\varepsilon$-martensite produced near the surface of TWIP steel is thermally induced $\varepsilon$-martensite rather than strain-induced $\varepsilon$-martensite. To produce thermal $\varepsilon$-martensite by water-cooling, a low value of stacking fault energy (SFE) is needed near the surface of TWIP steel ${ }^{17-19)}$. SFE depends on the chemical composition and deformation temperature $^{12,13)}$. In this study, chemical composition is the only factor affecting SFE due to which the effects of plastic deformation on the microstructure disappeared during recrystallization heat treatment.

The cross-section chemical composition was investigated from the surface in the depth direction. GDS was applied to analyze the surface compositions of $\mathrm{C}$, $\mathrm{Mn}$, and $\mathrm{Al}$ in TWIP and Al-TWIP steels. The surface-scale layer of approximately $10 \mu \mathrm{m}$ was removed to improve precision before GDS measurement. Fig. 6a shows the depth profile of carbon. Near the surface, the carbon contents of the TWIP and Al-TWIP steels were significantly lower than the original alloying composition. Al-TWIP steel had a larger content of carbon than TWIP steel. The carbon contents were restored to the value of $0.6 \mathrm{wt} \%$ while approaching the centers of the specimens. Carbon depletion near the surface was due to the decarburization that occurred at the surfaces of TWIP and Al- TWIP steels. Figs. $6 \mathrm{~b}$ and $6 \mathrm{c}$ indicate the depth profiles of $\mathrm{Mn}$ and $\mathrm{Al}$, respectively. $\mathrm{Al}$ and $\mathrm{Mn}$ contents were mostly constant in TWIP and Al-TWIP steels, regardless of thickness.
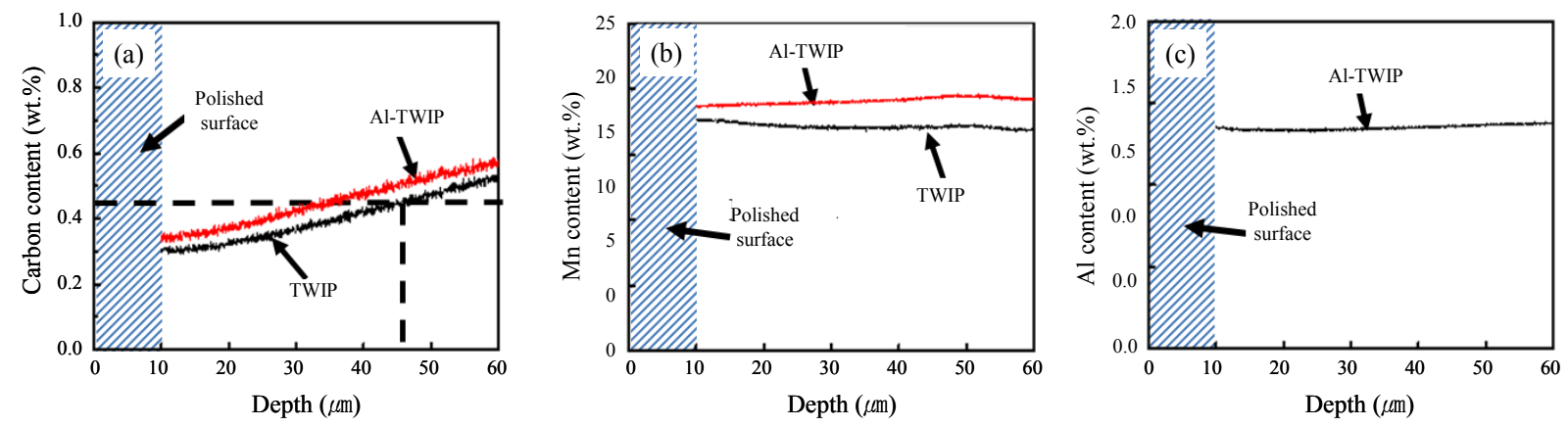

Fig. 6 GDS depth profiles of TWIP and Al-TWIP steels for (a) carbon, (b) manganese, and (c) aluminum 
Oxidation and decarburization reactions of steel materials are known to occur simultaneously in the reheating furnace $^{22)}$. Lee et al. investigated the oxidation behavior of Fe-18Mn-0.6C-1.5Al TWIP in a reheating furnace ${ }^{24)}$. The Mn content reduced in the surface-oxidized layer because of the formation of Mn oxide, but the Al content was mostly constant throughout the thickness. The demanganized layer from the previous study had a thickness of approximately $10 \mu \mathrm{m}^{23)}$. However, the martensite formed in the study had a thickness of approximately $45 \mu \mathrm{m}$. Hence, the thermally induced $\varepsilon$-martensite formed in TWIP steel was not entirely due to surface oxidation in the reheating and recrystallization furnaces. Thermally induced $\varepsilon$-martensite was generated because of surface decarburization in Fe-15Mn-2Cr-0.6C TWIP steel $^{24)}$. Schumann et al. calculated that thermally induced $\varepsilon$-martensite was generated when carbon was about $0.45 \mathrm{wt} \%$ or less in the Fe-18Mn-0.6C system $^{19)}$. However, the effect of $\mathrm{Al}$ on thermally induced $\varepsilon$ -martensite transformation was not investigated in the previous studies ${ }^{18,24)}$. Fig. 6a shows that $0.45 \mathrm{wt} \% \mathrm{C}$ of TWIP steel was achieved at a depth of approximately $45 \mu \mathrm{m}$ from the surface. The depth of $45 \mu \mathrm{m}$ matched the thickness of $\varepsilon$-martensite measured by XRD $(\sim 50 \mu \mathrm{m})$ and EBSD phase mapping $(\sim 40 \mu \mathrm{m})$, as indicated in Figs. 2 and 3a. Therefore, the formation of $\varepsilon$-martensite on the surface of TWIP steel can be explained by the decarburization phenomenon on the surface. Surface decarburization is closely related to the manufacturing process of TWIP steels because carbon increases the austenite stability of TWIP steel by increasing SFE ${ }^{25}$. In this study, slab reheating was conducted at $1200{ }^{\circ} \mathrm{C}$ for $1 \mathrm{~h}$ in air. It is an essential process for the removal of dendrite structures and securing the temperature for hot rolling ${ }^{2627)}$. Surface decarburization was expected because slab reheating was processed at high temperature under oxidizing conditions.

The decarburized layers produced from slab reheating remained at the surfaces of TWIP steel and Al-TWIP steel even after the completion of recrystallization heat treatment. Kim et al. measured the SFE of Fe-18Mn0.6C TWIP and Fe-18-Mn-0.6C-1.5Al TWIP steels by $\mathrm{TEM}^{13)}$. The SFE of Fe-18Mn-0.6C TWIP steel was 13 $\pm 3 \mathrm{~mJ} \mathrm{~m}^{-2}$ and that of Fe-18-Mn-0.6C-1.5Al was $30 \pm$ $10 \mathrm{~mJ} \mathrm{~m}^{-2}$. These compositions are nearly identical to those in this study. Therefore, the SFE values of this study can be considered the same as the SFE values derived from the previous study ${ }^{13)}$. The decarburized layer at the surface existed in both the TWIP and Al-TWIP steels, but the $\varepsilon$-martensite transformation occurred only in the TWIP steel. This was because austenite stability decreased due to decarburization at the surface of TWIP steel. In contrast, SFE increased with the addition of Al in TWIP steel and the austenite stability increased in the decarburization region, suppressing $\varepsilon$-martensite transformation in Al-TWIP steel.

\section{Conclusions}

This study investigated the thermally induced $\varepsilon$-martensite transformation at the surfaces of $\mathrm{Fe}-17.8 \mathrm{Mn}-0.57 \mathrm{C}$ (TWIP) and Fe-18.7Mn-0.61C-1.4Al (Al-TWIP) steels. The $\varepsilon$-martensite transformation occurred from the surface to a thickness of $\sim 45 \mu \mathrm{m}$ in TWIP steel. Near the surface, the carbon contents of the TWIP and Al-TWIP steels were significantly lower than the original alloying composition. Therefore, the $\varepsilon$-martensite transformation was caused by surface decarburization during the reheating process $\left(1200{ }^{\circ} \mathrm{C}\right.$ for $\left.1 \mathrm{~h}\right)$. Decarburization reduced the SFE and austenite stability at the surface. Although decarburization occurred at the surface of Al-TWIP steel, no $\varepsilon$-martensite transformation was observed because aluminum increased the SFE and austenite stability in the surface region. Carbon content of $0.45 \mathrm{wt} \%$ was achieved at a depth of $\sim 45 \mu \mathrm{m}$ from the surface for TWIP steel. The depth of $45 \mu \mathrm{m}$ coincided with the thickness of $\varepsilon$-martensite measured by XRD $(\sim 50 \mu \mathrm{m})$ and EBSD phase mapping $(\sim 40 \mu \mathrm{m})$.

\section{Acknowledgements}

This research was supported by a 2-year research grant of Pusan National University.

ORCID: Myungjin Lee: http://orcid.org/0000-0002-4757-4306 ORCID: Namhyun Kang: http://orcid.org/0000-0002-9460-5128

\section{Reference}

1. B. C. De Cooman, O. Kwon, K. Chin, State-of-theknowledge on TWIP steel, Mater Sci Technol. 28(5) (2012), 513-527 https://doi.org/10.1179/1743284711Y.0000000095

2. S. Lee, J. Kim, S. Kane, B. C. De Cooman, On the origin of dynamic strain aging in twinning-induced plasticity steels, Acta Mater. 59(17) (2011), 6809-6819 https://doi.org//10.1016/j.actamat.2011.07.040

3. O. Bouaziz, S. Allain, C. P. Scott, P. Cugy, D. Barbier, High manganese austenitic twinning induced plasticity steels, a review of the microstructure properties relationships, Curr Opin Solid State Mater Sci. 15(4) (2011), 141-168 https://doi.org/10.1016/j.cossms.2011.04.002

4. Y. Lee, Microstructural evolution during plastic deformation of twinning-induced plasticity steels, Scr Mater. 66(12) (2012), 1002-1006 https://doi.org/10.1016/j.scriptamat.2011.12.016 
5. S. Shin, J. Lee, S. Park, Strength Estimation Model of Resistance Spot Welding of 1.2GPa Grade Ultra High Strength TRIP Steel for Car Body Applications, Journal of Welding and Joining, 36(1) (2018), 82-89 https://doi.org/10.5781/JWJ.2018.36.1.10

6. C. Lee, S. Kim, T. Lee, C. Oh, Effects of Tramp Elements on Formability of Low-carbon TRIP-aided Multiphase Cold-rolled Steel Sheets, ISIJ Inter. 44(4) (2004), 737-743 https://doi.org/10.2355/isijinternational.44.737

7. H. Do, K. Cho, C. Oh, D. Suh, S. Kim, Effect of C Content on the Microstructures and Mechanical Properties of CMnSiAlCu TRIP-Aided Cold-Rolled Steel Sheets, $J$ Kor Inst Met Mater. 44(2) (2006), 99-108

8. J. Jin, C. Park, N. Kang, Isothermal Phase Transfor- mations and Stability of Retained Austenite during Quenching and Partitioning Process for 0.15C Steel, Journal of Welding and Joining, 35(1) (2017), 89-94 https://doi.org/10.5781/JWJ.2017.35.1.89

9. J. Yoo, B. Kim, Y. Park, C. Lee, Microstructural evolution and solidification cracking susceptibility of Fe-18Mn0.6C-xAl steel welds, J. Mater Sci. 50(1) (2015), 279-286 https://doi.org/10.1007/s10853-014-8586-4

10. L. M. Roncery, S. Weber, W. Theisen, Welding of twinning-induced plasticity steels, Scripta Mater. 66 (2012), 997-1001 https://doi.org/10.1016/j.scriptamat.2011.11.041

11. J. Park, J. Lee, G. An, S. Kim, H. Seo, Characteristic of Welding Rotational Deformation in Laser Welding of Thin Steel Sheet, Journal of Welding and Joining, 36(6) (2018), 1-7 https://doi.org/10.5781/JWJ.2018.36.6.1

12. S. Vercammen, B. Blanpain, B. C. De Cooman, P. Wollants, Cold rolling behaviour of an austenitic Fe-30Mn- 3Al3Si TWIP-steel, the importance of deformation twinning, Acta Mater. 52(7) (2004), 2005-2012 https://doi.org/10.1016/j.actamat.2003.12.040

13. J. Kim, S. Lee, B. C. De Cooman, Effect of Al on the stacking fault energy of Fe-18Mn-0.6 C twinning-induced plasticity, Scripta Mater. 65(4) (2011), 363-366 https://doi.org/10.1016/j.scriptamat.2011.05.014

14. K. Sato, M. Ichinose, Y. Hirotsu, Y. Inoue, Effects of Deformation Induced Phase Transformation and Twinning on the Mechanical Properties of Austenitic Fe-Mn-Al Alloys, ISIJ Int. 29(10) (1989), 868-877 https://doi.org/10.2355/isijinternational.29.868

15. S. Allain, J. P. Chateau, O. Bouaziz, A physical model of the twinning-induced plasticity effect in a high manganese austenitic steel, Mater Sci Eng A. 387-389 (2004), 143-147 https://doi.org/10.1016/j.msea.2004.01.060

16. G. Frommeyer, U. Brüx, P. Neumann, Super-ductile and high-strength manganese-TRIP, TWIP steels for high energy absorption purposes, ISIJ Int. 43 (2003), 438-446

https://doi.org/10.2355/isijinternational.43.438

17. P. Sahu, A. S. Hamada, C. S. Ghosh, L. P. Karjalainen, Structure and microstructure evolution during martensitic transformation in wrought $\mathrm{Fe}-26 \mathrm{Mn}-0.14 \mathrm{C}$ austenitic steel, an effect of cooling rate, J Appl Cryst. 40 (2007), 354-361 https://doi.org/10.1107/S0021889807005882

18. P. Sahu, A. S. Hamada, R. N. Ghosh, L. P. Karjalainen, $\mathrm{X}$-ray diffraction study on cooling-rate-induced gam$\mathrm{ma}(\mathrm{fcc}) \rightarrow$ epsilon(hcp) martensitic transformation in cast-homogenized Fe-26Mn-0.14C austenitic steel, Metall Mater Trans 38A. (2007), 1991-2000 https://doi.org/10.1007/s11661-007-9240-4

19. V. H. Schumann, Martensitische Umwandlung in aus- tenitischen Mangan-Kohlenstoff-Stählen, Neue Hütte 17 (1972), 605-609

20. X. Tian, H. Li, Y. Zhang, Effect of Al content on stacking fault energy in austenitic Fe-Mn-Al-C alloys, $J$ Mater Sci. 43(18) (2008), 6214-6222 https://doi.org/10.1007/s10853-008-2919-0

21. Y. Kim, N. Kang, Y. Park, I. Choi, G. Kim, S. Kim, K. Cho, Effects of the strain induced martensite transformation on the delayed fracture for Al-added TWIP steel, J Kor Inst Met Mater. 46(12) (2008), 780-787

22. I. Park, K. Jeong, J. Jung, C. Lee, Y. Lee, The mechanism of enhanced resistance to the hydrogen delayed fracture in Al-added Fe-18Mn-0.6C twinning-induced plasticity steels, Int J Hydrog Energy 37 (2012), 99259932

https://doi.org/10.1016/j.ijhydene.2012.03.100

23. J. Baud, A. Ferrier, J. Manenc, J. Benard, The oxidation and decarburizing of $\mathrm{Fe}-\mathrm{C}$ alloys in air and the influence of relative humidity, Oxide Met. 9 (1975), 69-97 https://doi.org/10.1007/BF00613495

24. D. Lee, P. Yadav, Oxidation of High Mn TWIP Steels in Reheating Furnace Condition. J Kor Inst Met Mater 53(12) (2015), 859-866

25. R. E. Schramm, R. P. Reed, Stacking fault energies of seven commercial austenitic stainless steels, Metall Mater Trans A. 6 (1974), 1345-1351 https://doi.org/10.1007/BF02641927

26. D. Lee, Evaluation of Optimal Residence Time in a Hot Rolled Reheating Furnace, World Acad Sci Eng Tech. 59 (2011), 1180-1184

27. H. T. Abuluwefa, Optimizing the process of steel slab reheating in pusher type reheat furnace prior to hot working, Applied Mechanics and Materials. 325 (2013), 364-370

DOI: 10.4028/www.scientific.net/AMM.325-326.364 